\title{
Optimal Placement of FACTS Devices: A Review
}

\author{
Ankita Singh, Shishir Dixit \\ Department of Electrical Engineering \\ Madhav Institute of Technology \& Science, Gwalior (M.P.) \\ ankita.singh980@gmail.com
}

\begin{abstract}
This review paper presents a bibliographical survey and review on Optimization Techniques for location of Flexible AC Transmission System in Power Systems. Flexible AC Transmission System (FACTS) are the electronic based compensation devices that may be helpful in meeting out requirement of electrical power up to some extent in a deregulated market. In this review Thyristor-Controlled Series Compensation (TCSC), Static Synchronous Compensator (STATCOM), Unified Power Flow Controller (UPFC), Unified Power Quality Conditioner (UPQC), Interline Power Flow Controller (IPFC) are considered to place optimally. The review is limited to optimal placement the of the FACTS devices for control strategy and stability of the power system networks for maximum benefits. The optimal placement of different FACTS devices with the different criteria of the objective function is considered for discussion.
\end{abstract}

Keywords-- FACTS devices; TCSC; STATCOM; UPFC; Optimal FACTS Placement.

\section{INTRODUCTION}

The ever increasing demand of electrical power and its quality are necessary in almost all the power systems but generation is limited due to high the fuel consumption and other constraints. The implementation of FACTS devices has the advantage of the reduction in reactive power supply, harmonics of source current. Also, it also helps in reduced bus voltage sag and swells, and power loss etc. Due to huge investment optimal location and sizing of FACTS devices are a must. In deregulated environment the unplanned power exchange to the main power grid may results in unhealthy to the system. The stability margins of the power system may be reduced due to this and rising the risk of cascading outages or an unstable system. In the deregulated power system poor system stability and voltage level are evident. In order to provide stable, reliable, efficient and secure operation of power system the placement of the FACTS devices should be optimal.

The optimal placement of the FACTS devices are provide increased real power flow in the system without increasing complexity in existing power generation network. Without incorporating additional lines the FACTS devices are capable to improve the system security by maintaining the voltage regulation, reducing the congestion by maintaining power flow regulation. The installation of the FACTS devices keeps the system stress free by maintaining voltage and the power regulation. The aim of the paper is to place of the FACTS devices optimally in the transmission system.

\section{CONSTRAINTS OF TRANSMISSION SYSTEM AND FACTS TECHNONOLGY}

\section{A. Transmission System Constraints}

The installation of the optimal FACTS devices in the transmission network allow the system to work very near to its stability and the thermal limits. The AC power system have inherent power stability as the power flow between the lines are dependent on the receiving and the sending end voltages. For a lossless line, which has the sending end voltage $V_{l}$, receiving end voltage $V_{2}, \theta_{1}$ and $\theta_{2}$ are the phase angles of the sending and receiving end respectively. The power flow equation can be given as

$$
P=\frac{V_{1} V_{2}}{X} \operatorname{Sin}\left(\theta_{1}-\theta_{2}\right)
$$

Where $X$ is the reactance of the line.

In the deregulated power generation environment the generation would be dependent to the environmental condition, fuel availability, economical conditions etc. At the same time the load also varies as per the climatic conditions, day timing, expansion etc. The variation in both the load and the generation may create a system security problem. For example the power system is operating very close to either its thermal or the stability limit, and even small sudden change in the system load or generation occurs, may result in power swings and even cascaded tripping. The increased load may upset the voltage regulation of the system and may lead to congestion also.

The various constrains that has to be take care are 
1. Transient Stability and voltage Limit

2. Dynamic Voltage Limit

3. Power Transfer Limit at Steady State

4. System Oscillation Damping limit

5. Thermal Limit

\section{Short Circuit Current limit}

These constraints would be applicable to almost all the transmission lines. Some transmission lines of the system would have two or more of the above limits reached. Increasing power delivery by the power generation units can solve all these problems. But, there is economical and the environmental constraints involve in increasing the power generation units. In spite of increasing power generation units, FACTS devices may be used. These devices can control the real and the reactive power dynamically, may provide the support to the system to a major extent. The conventional devices which are mostly used for the power system problems are series capacitor, switched reactor and capacitor, the voltage regulation, phase shifting transformer which are used for the angle variation, synchronous condenser for controlling the voltage.

\section{B. FACTS Technology}

Thermal loading limits are highly important for transmission lines. At the same time transmission stability limits, voltage limits and the loop flows are also take care not to reach the thermal limits [41-43].

FACTS devices are power electronic based technology and are capable to the power flow in the power system. The benefits of use of the FACTS devices:

1. The dynamic characteristics of FACTS devices help in rapid real and reactive power control

2. The reduced in congestion the network

3. The continuous compensation can be achived

4. System voltage profile and power loss can be controlled

5. The problem of lines overloading can be minimized with voltage compensation

6. Transient stability can be improved

As can be seen from equation (1) the FACTS devices control various parameters of systems like the impedance, the power angles in order to contain the voltage and power regulations.

Widely used FACTS devices to control the voltage in the transmission lines are Static VAR Compensator (SVC) and STATCOM. TCSC controls the impedance, Thyristor Controlled Phase Shifting Transformer (TCPST) Controls angle. The other FACTS devices which can control above parameters are UPFC, IPFC and Static Synchronous Series Controller (SSSC).

Different installation issues of the FACTS devices are the cost, sizing of the devices and different control during transient and steady state.

The FACTS devices and its controlling action on the variables which would control the transient limits, voltage limits are as given below. The topology of STATCOM is as given below.

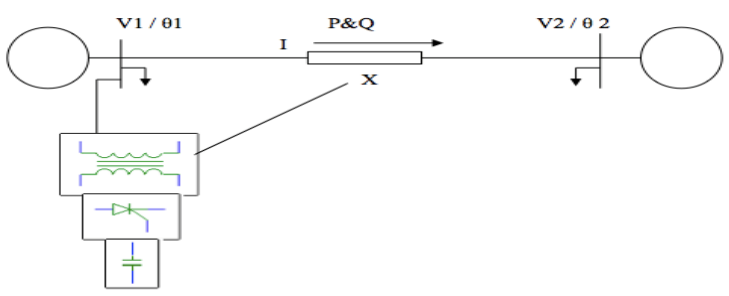

Figure 1. STATCOM Topology

The STATCOM topology in Figure 1 explains that the term is controlled in the equation (1), which would be the voltage compensation. This indirectly compensates the reactive power as the reactive power can be defined as in equation (2).

$$
P=\frac{\left(V_{1}-V_{2}\right) V_{1}}{X} \cos \left(\theta_{1}-\theta_{2}\right)
$$

It can be seen from the equation (2) that if there were any difference in the voltage of the sending and the receiving end then the reactive power would increase with increase in the difference. Thus the voltage limit that has to be compensated by the STATCOM should be designed accordingly.

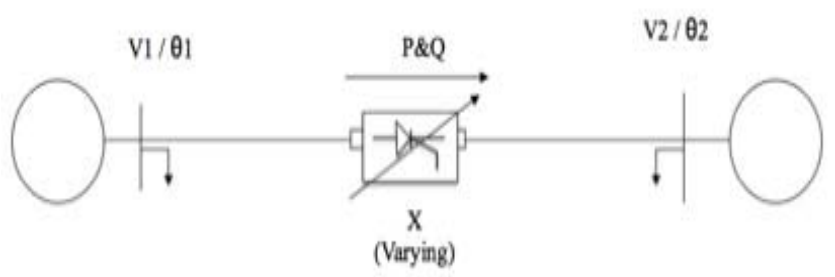

Figure 2.TCSC Topology

The TCSC topology defines that in the two bus system considered the value of the reactance varies in order to control the power flow by line impedance compensation.

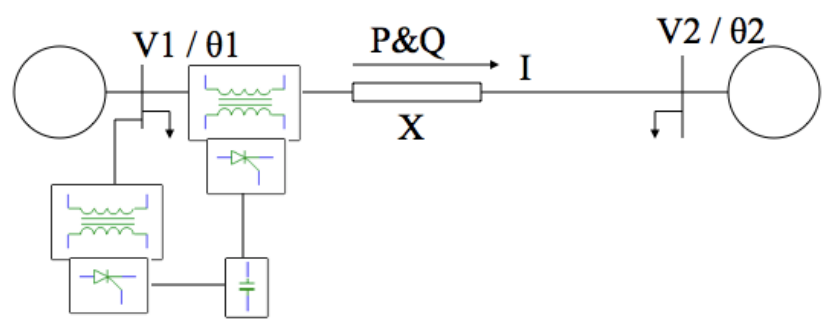

DOI- 10.18486/ijcsnt.2014.3.3.02

ISSN-2053-6283 


\section{Figure 3. UPFC Topology}

Figure 3.UPFC Topology The overall power flow of the transmission system is controlled by the use of regulating the bus voltage and also injecting the voltage in series to the line.

\section{OBJECTIVES OF PLACEMENT OF FACTS DEVICES}

The optimal location of the FACTS device is an important issue while the installation of the devices is considered

The important factors that are considered while its placement in the power system constraints are.

1. Minimization of power loss in the transmission system.

2. Minimization of reactive power loss.

3. Congestion management.

4. Improved Power transfer capability.

\section{OPTIMAL PLACEMENT OF FACTS DEVICES -A REVIEW}

Meta Heuristic Algorithms like Genetic Algorithm (GA), Particle Swarm Optimization (PSO), and Harmonic Search Algorithm (HSA) are optimization techniques used for the placement of the FACTS devices. The optimal placement, selection and sizing of device in order to minimize both the generation cost and FACTS devices cost using the HSA and GA algorithms [1]. Power transfer capability and the voltage regulation are considered placement of both devices the TCSC and the SSSC under both normal conditions and contingency condition. A comparative study has been explored between TCSC and SSSC [2]. In order to increase the profit of the private supplier in the deregulated environment and also to improve load ability the optimal location of FACTS has been find out [3]. Voltage stability improvement and the power loss minimization are considered as the objective function [4], for placement of FACTS devices using the GA. Enhancing the security of the power system during contingency or minimizing the bus voltage deviation by placement of UPFC has been carried out in implementing PSO and GA algorithm[5]. The placement of multi FACTS SVC and TCSC on the transmission line to improve the voltage stability using the GA [6]. For Optimal Power Flow (OPF) placement of the FACTS has been done considering as the constraint by device-using GA, for a improved power flow without violation of the limits [7]. Sensitivity analysis and the extended equal area criterion have been implemented as the objective function for the optimal placement of FACTS devices in order to improve the

DOI- 10.18486/ijcsnt.2014.3.3.02

ISSN-2053-6283 voltage as well as transient stability [8]. In the deregulated environment, optimal location, size and number of FACTS devices has been considered to be optimized in the power system [9].

For improved Power system load ability, by optimal placing multiple TCSC devices using optimization algorithm PSO and GA [11][12][14] [18]. The controlling active and the reactive power and voltage regulation of the system placement of UPFC devices using GA has been carried out [13]. The power quality management including load ability and the loss minimization has been is carried out in [15]. The optimal placement of UPFC using linear and the nonlinear load [16]. The total cost including the generation cost and the cost of FACTS has been considered for placement of FACTS devices with GA as the optimization algorithm [17].

The forecasting of reactive power for the large transmission system with private power suppliers has been considered using GA [19-20].

In [21] the Tabu Search (TS), Simulated Annealing (SA) and the GA methods has been explored for the optimal placement of TCSC, TCVR, TCPST, SVC and UPFC. Implementation of all these algorithms provided the same results for the placement of the FACTS devices. In order to compare the increase in load ability when single and multiple FACTS devices has been used [22]. The collapse point has been analyzed by using the continuous power flow applied on the power system by placing the FACTS devices using the GA [23]. For the shunt compensating devices while used in the long distance transmission lines it has been found that the optimal placement of the FACTS devices lie at the center of the transmission line. In [24] it has been proved that the shunt FACTS device when placed slightly before or after the center the power transfer capability has improved.

In [25] the sensitivity analysis has been implemented for considering the reactance that the TCSC has to bear while the optimal location of the TCSC has been carried out. The optimal placement of TCSC and SVC has been carried out in order to enhance the power transfer capability with sensitivity approach [26].

The Meta heuristic methods have been combined in order to get the better convergence to improve the computational and the optimization benefits. The placement of STATCOM has been done using hybrid Meta heuristic algorithm combining the Ant Colony Optimization (ACO) and GA. The optimization has the objective of finding the best location and capacity of the STATCOM device [27]. The ACO got improved convergence while the GA is fused with the ACO.

A Multi-objective Fuzzy (MOF) has been combined with the GA in order to find a optimal location and size of shunt 
FACTS controllers. The objective is to increase the distance to saddle node bifurcation and improve bus voltage profile [28].

The hybrid algorithm that combines the TS and the SA approach has been implemented to get the optimal location for multiple FACTS devices [29].

The multi objective particle swarm optimization for optimal allocation of the SVC by the mixed continuous discrete multi objective optimization problem [30]. Enhancement in stability, reduction real power loss voltage deviation is observed.

For the lower cost of installation and system stability as the optimization constraints the PSO has been used on SVC, TCSC and UPFC devices. [31].

The Time Varying Accelerating Constant (TVAC) has been implemented for the optimization, which gives an optimal location, and size of the STATCOM [32].

PSO algorithm has been compared for ideal location and sizing of STATCOM, PSO-TVAC has been found better in providing computation speed and solution quality [32]. Continuous Power flow for placement of the UPFC to increase load ability has been discussed [33].

Mixed Integer programming with PSO for optimizing the power flow [34], Honey Bee Mating Optimization (HMBO) for parameter tuning of the TCSC and SVC placement [35], Non Dominated Sorting Improved Harmony Search (NSHIS) with crowding distance strategy [36], Line Flow Overload Sensitivity Index (LFOSI) based optimization for TCSC controller [37], Graphical User Interface with GA as the optimization technique for the placement in order to choose the different FACTS devices like SVC, UPFC, TCPST placing in multiple locations are developed with different constraints user defined[38].

MATLAB implementation of PSO optimized FACTS device with and without wind energy to enhance load ability and minimize in power loss has been discussed and compared [39] Congestion management using Differential Evolution (DE) with Fuzzy logic controller [40].

\section{CONCLUSION}

The review of different optimal Placement methods has been presented available in literature. The different series and shunt FACTS devices like SVC, STATCOM, IPFC, TCSC UPFC, with different objective function has been placed optimally with different algorithms. The different hybrid optimization algorithm for the optimal placement of FACTS devices has also been discussed in the transmission system are discussed.

\section{REFERENCES}

[1] Prashant Kumar Tiwari and Yog Raj Sood, "Optimal Location of FACTS Devices in Power System Using Genetic Algorithm", NaBICWorld Congress Conference, 2009, pp. 1034-1040.

[2] V.P.Rajderkar and V.K.Chandrakar, "Comparison of series FACTS Devices Via Optimal Location in a Power System for Congestion Management”, APPEEC Conference, 2009, pp. 534543.

[3] M.Majidi Q, S. Afsharnia, M.S.Ghazizadeh, A.Pazuki, "A New Method for Optimal Location of FACTS Devices in Deregulated Electricity Market", IEEE Electrical Power and Energy Conference, 2008, pp. 344-350.

[4] H.R.Baghaee, M.Jannati, B.Vahidi, "Improvement of Voltage Stability and Reduce Power System Losses by optimal GAbased Allocation of Multi-type FACTS Devices", OPTIM International Conference, 2008.

[5] H.I. Shaheen, G.I.Rashid, S.J. Cheng, Sr. Member, IEEE, "Optimal Location and Parameters Setting of UPFC based on GA and PSO for enhancing power system security under single Contingencies", Power and Energy Society General Meeting Conversion and Delivery of Electrical Energy in the 21st Century, IEEE conference 2008, pp. 208-216.

[6] H.R.Baghaee, M.Jannati, B.Vahidi, "Optimal Multi-type FACTS Allocation using Genetic Algorithm to improve power System Security", 12th International Middle-East Power System Conference, MEPCON, IEEE Conference, 2008, pp. 162-166

[7] M.M.El Metwally, A.A.El Emary, "Optimal Allocation of FACTS Devices in power system using Genetic Algorithms", 12th International Middle-East Power System Conference, MEPCON, IEEE Conference 2008, pp. 312-315.

[8] Feng Qian, Guangfu Tang and Zhiyuan He, "Optimal Location and Capability of FACTS Devices in a power system by means of sensitivity analysis and EEAC”, DRPT 2008, pp. 2100-2104

[9] M.Gitizadeh and M. kalantar, "A New Approach for Congestion Management via optimal Location of FACTS Devices in Deregulated Power Systems", Third International Conference on Electric Utility Deregulation and Restructuring and Power Technologies, DRPT 2008. IEEE Conference 6-9 April 2008 DRPT, Nanjing China, pp. 1592 - 1597.

[10] K.Vijaykumar, Dr.R.P.Kumudinidevi, D. Suchitra, "A hybrid Genetic Algorithm for Optimal Power Flow incorporating FACTS Devices", International Conference on Computational intelligence and Mutimedia Applications 2007, pp. 463 - 467.

[11] G.I.Rashid, H.I.Shaheen, IEEE student member, "Optimal Location and Parameter Settings of Multiple TCSCs for Increasing Power System Loadability based on GA and PSO Techniques", Third International Conference on Natural Computation (ICNC 2007).

[12] G.I. Rashed, H.I. Shaheen, S.J.Cheng, Senior Member, "Optimal Location and Parameter Setting of TCSCs by both Genetic Algorithm and and Particle Swarm Optimization", 2nd IEEE 
Conference on Industrial Electronics and Applications,IEEE Conference 2007, pp. 1141 - 1147.

[13] D. Arabkhburi, A. K,azemi, M.Yari, "Optimal Placement of UPFC in power system using Genetic Algorithm", IEEE International Conference on Industrial Technology, ICIT 2006 , pp. 815-821.

[14] Kazami, D. Arabkhburi, M.Yari, "Optimal Placement of UPFC in power system for increasing Loadability using Genetic Algorithm", IEEE International Conference on : Industrial Technology, ICIT 2006.

[15] Belkacern Mahdad, Tarek Bouktir and Kamel Srairi, " Strategy of Location and Control of FACTS Devices for enhancing Power Quality", IEEE Mediterranean Electrotechnical Conference, 2006. MELECON 2006, May 16-19, Spain.

[16] S.Ali Ai mawsawi and M.R. Qader, " Comparison of Optimal Location of UPFC applied to Linear and Nonlinear Load model", The 8th IEE International Conference on AC- DC Transmission (ACDC 2006), pp. 204 - 209.

[17] A.A. Abduljabbar, J.V. Milanovic, UK, “ GA based Optimization for allocation of static VAr Compensators", The 8th IEE International Conference on AC and DC Power Transmission, ACDC 2006. IEEE 2008 Conference, pp. $115-$ 120.

[18] M. Saravanan, S. Mary Raja Slochanal, “Application of PSO for Optimal Location of FACTS considering system loadability and cost of installation", The 7th International Power Engineering Conference, IEEE,IPEC 2005.

[19] L.J.Cai, Ielrich, "Optimal Choice and Allocation of FACTS devices in deregulated electricity market using GA", Power Systems Conference and Exposition, IEEE PES 2004.

[20] Narayan Prasad padhye and Abdel moamen M.A., "Optimal location and initial parameter setting of multiple TCSCs for reactive power planning using GA", PES General Meeting, 2004.

[21] S. Gerbex, R. cherkaoui and A.J. Germond, "Optimal Location of FACTS devices to enhance power system security", 2003 IEEE Bologna Power Tech Conference Italy, pp. 822 -827.

[22] Stephane Gerbex and Rashid Cherkaouri, Member IEEE, "Optimal location of multi-type FACTs devices in a power system by means of Genetic Algorithm", IEEE Transactions on Power Systems, August 2001, pp. 537- 544.

[23] M. Karami, N. Marium and M.Z.A. Ab Kadir, "Determining Optimal Location of Static Var Compensator by Means of Genetic Algorithm", International Conference on Electrical, Control and Computer Engineering, Malaysia, June 2011, pp. 303- 310 .

[24] M.H. Haque, "Optimal Location of shunt FACTs devices in long transmission lines", IEE 2000 proceeding online no. 20000412 , pp. $218-222$.

[25] Dr.N.D.Ghawaghawe and Dr.K.L. Thakre, "Computation of TCSC reactance and suggesting criterion of its location for ATC

DOI- 10.18486/ijcsnt.2014.3.3.02

ISSN-2053-6283 improvement", Electrical Power and Energy Systems (2009) pp. 86-93.

[26] G.Swapna, J.Shriniwas Rao, J.Amarnath, "Sensitivity Approach to improve Transfer capability through optimal placement of TCSC and SVC", International Journal of Advances in Engineering and Technology, July 2012, pp. 525-536.

[27] Whei-Min Lin, Kai-Hung Lu, Cong-Hui Huang, Ting-Chia Ou, and Yuan-Hui Li, "Optimal Location and Capacity of STATCOM for Voltage stability Enhancement using ACO plus GA," IEEE/ASME International Conference on Advanced Intelligent Mechatronics, pp.1915-1920, 2009.

[28] A R. Phadke, ManojFozdar, K. R. Niazi, "Multi-objective Fuzzy-GA Formulation for Optimal Placement and Sizing of Shunt FACTS Controller,"Third International Conference on Power Systems, pp.1- 6, December 2009.

[29] P. Bhasaputra and W. Ongsakul, "Optimal placement of multitype facts devices by hybrid TS/SA approach," Circuits and Systems, 2003. ISCAS '03. Proceedings of the 2003 International Symposium on vol.3, pp. 375-378,2003.

[30] Abdelaziz Laifa, Mohamed Boudour, "Facts allocation for power system voltage stability enhancement using MOPSO," 5th International Multi-Conference on Systems, Signals and Devices, pp.1-6,2008.

[31] M. Saravanan, S. Mary Raja Slochanal, P. Venkatesh, J. Prince Stephen Abraham, "Application of particle swarm optimization technique for optimal location of FACTS devices considering cost of installation and system loadability," International journal of Electric Power Systems Research,vol. 77, pp. 276-283,2007.

[32] Varshney S., Srivastava L., Pandit M., "Optimal placement and sizing of STATCOM for voltage security enhancement using PSO-TVAC," International Conference on Power and Energy Systems, pp.1-6, Dec. 2011.

[33] Optimal placement of FACTS devices for voltage stability using line indicators Anju Gupta; P. R. Sharma 2012 IEEE Fifth Power India Conference Year: 2012 Pages: 1 - 5

[34] Optimal Placement of a Shunt FACTS Controller in Java-Bali 24-Bus Indonesian System by Evolutionary Optimization TechniqueI. Made Wartana; Ni Putu Agustini 2013 1st International Conference on Artificial Intelligence, Modelling and SimulationYear: 2013 Pages: 376 - 380

[35] Simultaneous optimal placement and parameter-tuning of SVC, TCSC and PSS using Honey-Bee Mating Optimization Hossein Shayeghi; Mohammad Moradzadeh; Ali Ghasemi; Lieven Vandevelde 2013 IEEE PES Asia-Pacific Power and Energy Engineering Conference (APPEEC) 2013 Pages: 1 - 5

[36] Abdelaziz Laïfa; Ammar Medoued "Optimal FACTS location to enhance voltage stability using multi-objective harmony search", 3rd International Conference on Electric Power and Energy Conversion Systems, 2013 ,Pages: 1 - 6

[37] G. Balamurali; K. Thanushkodi "Practical power system operation criterionandexpansionplanningbased optimal placement of facts controllers",International Conference on 
Current Trends in Engineering and Technology (ICCTET) 2013,PP: 291 - 295

[38] Esmaeil Ghahremani; Innocent Kamwa“'Optimal placement of multiple-type FACTS devices to maximize power system loadability using a generic graphical user interface" IEEE Transactions on Power Systems,2013, Volume: 28, Issue: PP:2764 - 778

[39] A. Prasanthi; Sindhu T. K,"Optimal placement and rating of FACTS devices for congestion management in power system without and with wind energy integration", IEEE International Conference on Advanced Communications, Control and Computing Technologies,2014,PP: 224 - 229

[40] Biplab Bhattacharyya; Vikash Kumar Gupta; Sanjay Kumar, "Fuzzy-DE approach for the optimal placement of FACTS devices to relief congestion in a power system" Proceedings of
The 2014 International Conference on Control, Instrumentation, Energy and Communication (CIEC), 2014, PP: 291 - 295

[41] I J Nagrath and D P Kothari, "Modern Power System Analysis" a book by Tata McGraw Hill, New Delhi, pp. 01- 308.

[42] D P Kothari and J S Dhillon, “ Power System Optimization”, a book by Prentice Hall of India, New Delhi, pp. $56-218$.

[43] K R Padiyar, "Power Systems Dynamics", a book by BS Publications, Hyderabad, pp. 01-205.

[44] Hingorani, "FACTS Controllers in Transmission and Distribution Systems", pp. 1-76. 